\title{
Strategi SMP Angkasa Lanud Padang dalam Menanamkan Nilai- Nilai Nasionalisme melalui Program Cinta Dirgantara
}

\author{
Delvia Yurmanita, Azwar Ananda \\ Prodi Pendidikan Pancasila dan Kewarganegaraan \\ FIS Universitas Negeri Padang \\ E-mail: Gyugykyu12109@gmail.com
}

\begin{abstract}
ABSTRAK
Penelitian ini bertujuan untuk menggambarkan penanaman nilai nasionalisme di SMP Angkasa Lanud Padang melalui Program Cinta Dirgantara. Pengamalan nilai nasionalisme dapat tergambar melalui sikap rela berkorban, cinta tanah air, berjiwa pemeaharuan, pantang menyerah, mengutamakan persatuan dan kesatuan. Metode yang digunakan dalam penelitian adalah metode kualitatif, dan data diperoleh melalui wawancara, observasi dan studi dokumen. Hasil penelitian di SMP Angkasa menunjukkan bahwa, strategi SMP Angkasa menanamkan nilai nasionalisme melalui program cinta dirgantara adalah melalui kegiatan-kegitan yang dilakukan bersama dengan TNI-AU. Beberapa indikator sikap nasionalisme belum mampu terpenuhi oleh siswa, masih ditemui siswa yang tidak mengikuti aktivitas seperti UBHS dengan baik dan kurangnya disiplin siswa. Kurangnya fasilitas untuk melaksanakan program menjadi hambatan utama sekolah, terutama transportasi untuk membawa semua siswa menyambut pesawat. TNI-AU berperan sebagai pelatih dalam ekskul pramuka dan paskibra. Selain itu TNI-AU juga dapat menjadi contoh pengamalan nilai nasionalisme di kehidupan kepada siswa.
\end{abstract}

Kata Kunci: nasionalisme, Cinta Dirgantara, SMP Angkasa

\section{ABSTRACT}

This study aims to describe the planting of nationalism in Padang Angkasa Lanud Middle School through the Cinta Dirgantara Program. The practice of the values of nationalism can be illustrated through the attitude of self-sacrifice, love for the motherland, renewed spirit, never giving up, prioritizing unity and unity. The method used in this research is a qualitative method, and data obtained through interviews, observations and study documents. The results of the research at SMP Angkasa show that, SMP Angkasa's strategy to instill the value of nationalism through the aerospace love program is through activities carried out jointly with the Indonesian Air Force, some indicators of nationalism attitude have not been able to be fulfilled by students, still found students who do not participate in activities such as UBHS well and lack of student discipline. The lack of facilities to carry out the program becomes the main obstacle for schools, especially transportation to bring all students to welcome the plane. The Indonesian Air Force plays the role of trainer in 
scout and post-combat extracurricular activities. In addition, the Air Force can also be an example of the practice of the value of nationalism in life to students.

Keywords: Nationalism, aerospace, program, Angkasa junior high school

(c) (i) (2) This work is licensed under the Creative Commons Attribution-ShareAlike 4.0 International License. Brist author. 


\section{PENDAHULUAN}

Revolusi komunikasi dan teknologi telah melahirkan globalisasi yang membuat dunia seakan menjadi kampung besar, dimana batas-batas negara menjadi kabur. Interaksi antar budaya pun tidak dapat dielakan dan semakin intensif. Akibatnya perilaku dan sikap masyarakat Indonesia pun tercemari oleh budaya asing terutama pada remaja dan masyarakat perkotaan. Besarnya pengaruh budaya asing yang tidak dapat terbendung mengakibatkan sendi-sendi kehidupan masyarakat dan bangsa menjadi rapuh. Tidak sedikit individu yang menganut pola budaya barat dan meninggalkan budayanya sendiri. Dengan sendirinya mereka kehilangan identitas kebangsaannya. Keadaan ini akan melahirkan inferioritas (rasa rendah diri) nasionalisme Indonesia terhadap pengaruh dan hegemoni budaya asing. Memudarnya rasa nasionalisme dapat menjadi suatu ancaman bagi suatu negara, karena dapat menyebabkan kehancuran negara dari dalam. Hal itu terjadi karena ketahanan nasional yang lemah dan dapat dengan mudah ditembus oleh pihak luar. Banyak sekali paham dan budaya barat yang masuk dan memberi pengaruh negatif dan bercampur dengan budaya lokal. Dengan terjadinya hal tersebut akan terjadi akulturasi, bahkan menghilangnya kebudayaan dan kepribadian bangsa yang seharusnya menjadi jati diri negara.

Maka, pembinaan terhadap generasi muda menjadi warganegara yang baik menjadi perhatian utama. Oleh karena itu, tugas bagi para pendidik, pembuat kebijakan, dan anggota civil society lainnya adalah mengkampanyekan pentingnya Pendidikan Kewarganegaraan kepada seluruh lapisan masyarakat dan semua instansi dan jajaran pemerintahan. Penanaman nilai-nilai nasionalisme melalui program Pendidikan Kewarganegaraan merupakan perkara yang perlu dilakukan secara berkelanjutan demi menjamin keberlangsungan kehidupan negara-bangsa (Budimansyah, 2010).

Program penanaman nasionalisme di sekolah biasanya dilakukan melalui pembiasaan menyanyikan lagu kebangsaan Indonesia Raya pada upacara bendera yang rutin dilakukan pada hari Senin atau pada hari-hari besar seperti pada peringatan kemerdekaan Indonesia. Ekstrakurikuler seperti Pramuka dan Paskibra yang diikuti oleh siswa juga menjadi wadah penanaman nilai nasionalisme. Penanaman nilai nasionalisme di 
Sekolah Angkasa terutama dalam penelitian ini SMP Angkasa Lanud Padang, juga menggunakan metode yang sama dengan sekolah pada umumnya. Namun, SMP Angkasa Lanud Padang memiliki program khusus yang bernama Cinta Dirgantara. Melalui program tersebut, terdapat peran TNI- AU dalam memberikan contoh sikap nasionalisme, melalui kegiatan yang dilakukan bersama siswa seperti upacara bendera, ekskul Pramuka dan Paskibra. Serta acara seperti menyambut Pesawat TNIAU yang akan mendarat di Lanud ataupun di bandara.

Melihat upaya yang dilakukan oleh SMP Angkasa Lanud Padang dalam menanamkan nilai nasionalisme maka memberikan pertanyaan bagaimana Program Cinta Dirgantara mampu meningkatkan sikap nasionalisme dalam diri siswa, bagaimana peran TNI-AU dalam pelaksanaan program tersebut. Manfaat penelitian ini adalah untuk memberikan gambaran bahwa penanaman nasionalisme merupakan hal yang sangat penting pada masa sekarang dan sekolah melakukan berbagai program dan kegiatan itu, salah satunya program cinta dirgantara bersama dengan TNI-AU.

\section{METODE PENELITIAN}

Metode penelitian menggunakan metode kualitatif. Penelitian kualitatif menurut Bogdan dan Tylor (1975) dalam Moleong (2012:4) mendefinisikan metode penelitian kualitatif sebagai prosedur penelitian yang menghasilkan data deskriptif berupa kata-kata tertulis atau lisan dari orang-orang dan perilaku yang dapat diamati. Dengan teknik pengumpulan data melalui wawancara dengan narasumber dan studi dokumen. Penelitian dilakukan di SMP Angkasa Lanud Padang yang berada di yang berlokasi di Jl. Prof. Dr.Hamka Parupuk Tabing, Kecamatan Koto Tangah, Kota Padang. Kegiatan wawancara dan studi dokumen dilakukan selama 2 bulan.

Moleong (1989) menegaskan bahwa informan penelitian adalah orang yang dimanfaatkan untuk memberikan informasi tentang situasi dan kondisi latar penelitian. Maka dari itu dipilih 5 orang siswa (2 siswa perempuan dan 3 siswa laki-laki) yang secara aktif ikut kegiatan program cinta dirgantara. Kemudian seorang guru PPKn, kepala SMP Angkasa Lanud Padang serta 3 orang perwira TNIAU. Untuk mendukung data wawancara penulis juga melakukan observasi pada sikap dan kegiatan yang dilakukan oleh siswa. Miles dan Huberman (1992) 
dalam Baswori dan Suwandi (2008;209) menegaskan, bahwa analisis data pada penelitian kualitatif dilakukan dalam 3 langkah yaitu; Reduksi data yaitu memelih data yang akan disimpulkan dan diverivikasi. Penyajian data biasanya dalam bentuk teks naratif, serta penarikan kesimpulan/verifikasi.

\section{HASIL DAN PEMBAHASAN}

\section{Pelaksanaan program cinta dirgantara}

Penanaman nasionalisme dilakukan melalaui pengembangan pengalaman belajar dan proses belajar yang bermuara pada pembentukan karakter dalam diri peserta didik (Kusnaedi, 2016). Penanaman nasionalisme oleh SMP Angkasa dilakukan melalui program cinta dirgantara yang diintegrasikan dalam mata pelajaran PKN dan juga ekskul Pramuka dan Paskibra. Hal ini sejalan dengan aspek nasionalisme menurut Apter dalam (Adisusilo, n.d.) yang menyatakan bahwa nasionalisme dibagi menjadi 3 aspek yaitu cognitiv, goal, strategic. Dimana pada program ini ada aspek cognitiv dimana guru dalam hal ini memberikan gambaran dan situasi konkret pada bidang sosial, ekonomi politik dan budaya bangsanya.

Maka peran guru sebagai kaum intelektual dalam pembentukan nasionalisme sangat penting. Pada aspek goal juga guru memberikan gambaran cita-cita yang ingin dicapai dimasa depan dalam berbagai aspek seperti aspek sosial, budaya, politik dan ideologi. Pada aspek strategic penanaman sikap nasionalisme dilakukan melalui program cinta dirgantara sebagai bentuk perjuangan sekolah bersama dengan TNI-AU untuk memperkuat sikap nasionalisme siswa. Sejalan dengan yang dikemukakan (Mulyasa, 2003) bahwa pendidikan karakter dapat diintegrasikan dalam seluruh pembelajaran pada setiap bidang studi yang terdapat pada kurukulum.

Di sekolah upaya penanaman nilai nasionalisme biasanya dilakukan melalui mata pelajaran Pendidikan Kewarganegaraan. Penanaman nasionalisme dapat dilakukan melalui 2 aspek yaitu melalui pewarisan dan peneladanan. Pewarisan yang dimaksud adalah peserta didik diberikan pengetahuan tentang pentingnya sikap nasionalisme dan patriotisme di Indonesia. Dan yang kedua adalah peneladanan secara nyata di sekolah setiap hari Senin akan dilakukan upacara bendera. Apabila siswa ada yang tidak serius dalam mengikuti kegiatan tersebut maka guru akan mengambil tindakan agar siswa tersebut tetap 
disiplin. Hal ini dilakukan agar siswa tidak berperilaku menyimpang utamanya untuk membentuk karakter peserta didik (Rawintina \& Arsana, 2013).

Ektrakurikuler bertujuan untuk mengembangkan minat dan bakat serta mengembangkan potensi siswa. Salah satu kegiatan yang ekstrakurikuler yang memiliki peran dan pengaruh dalam pembentukan karakter, moralitas, serta menanamkan sikap nasionalisme adalah pasukan pengibar bendera (Paskibra) (Fibrianto \& Bakhri, 2018). Paskibra SMP Angkasa tidak jarang juga dilatih oleh para anggota TNI-AU. Walaupun waktu latihan bersama dengan TNI-AU tidak dapat ditentukan, penanaman sikap nasionalisme dilakukan ketika latihan berlangsung.

Ekstrakulikuler merupakan kegiatan yang dilakukan pada siswa sekolah menengah di luar jam pembelajaran di dalam kelas. Kegiatan yang dilaksanakan tersebut, fungsi utama ialah mengembangkan bakat, minat, memperluas pengetahuan, belajar bersosialisasi, menambah keterampilan dan mengisi waktu luang dengan hal positif.

Pramuka merupakan salah
satu ekstrakurikuler $\begin{array}{r}\text { yang } \\ \text { mampu }\end{array}$
$\begin{aligned} & \text { diharapkan } \\ & \text { mengembangkan karakter siswa, }\end{aligned}$

maka kegiatan ini menjadi wajib diikuti oleh setiap siswa. Sehingga dapat mendorong kemampuan siswa terhadap lingkungan sekitarnya. Kepramukaan adalah sistem pendidikan kepanduan yang disesuaikan dengan keadaan, kepentingan, dan perkembangan masyarakat dan bangsa Indonesia. (Nihayah \& Adi, 2014)

\section{Pramuka SMP Angkasa} merupakan bagian dari program cinta dirgantara di sekolah tersebut. Dimana pramuka SMP Angkasa dilatih oleh TNI-AU dan tidak jarang bergabung dengan sekolah lain. Melalui penggabungan maka dapat meningkatkan adaptasi siswa terhadap lingkungannya. Selain itu dengan latihan bersama TNI-AU memberikan contoh sikap-sikap disiplin, cinta tanah air dan pantang menyerah yang ada dalam pewira TNI-AU tersebut. Hal ini sejalan dengan pendapat Didin (Aulia \& Trihantoyo, 2019) bahwa metode keteladanan merupakan metode pemodelan dengan cara pendidik memberi contoh teladan baik kepada anak agar dapat di tiru dan dilaksanakan. Keteladanan adalah metode yang efektif dalam membentuk dan mempersiapkan pendidikan karakter bagi anak. Selain pramuka dan paskibra, aktivitas seperti menyambut pesawat TNI-AU yang mendarat juga menjadi salah kegiatan pemodelan yang dilakukan dengan 
melihat secara langsung figur para TNI-AU yang datang walau tidak dilakukan secara rutin. Sikap yang ditunjukkan oleh para TNI-AU didepan siswa, seperti sikap disiplin, mengikuti kegiatan dengan antusias, penuh semangat menjadi sebuah model bagaimana sikap yang harus ada pada diri siswa.

Pada dasarnya penumbuhan nilai karakter nasionalisme itu tidak terlepas dari dari pembiasaan. Sekolah harusnya memegang peranan penting terkait dengan masalah ini. Sekolah membangun dasar-dasar karakter nasionalisme tidak hanya melalaui kurikulum pembelajaran, akan tetapi juga melalui pembiasaan pada kegiatan ekstra/ko/intra atau non kulikuler, seperti Upacara Bendera, Pramuka, dan lain sebagainya. Tidak hanya itu budaya sekolah yang dibangun seperti disiplin, kebersihan, saling menghormati, atau menghargai dan lainnya juga bisa dijadikan sebagi simpul-simpul pembiasaan penumbuhan nilai karakter nasionalisme. (Bakar et al., 2018).

Dalam proses pelaksanaan program cinta dirgantara ditemui berbagai hambatan yang dihadapi oleh sekolah. Hambatan yang paling umum adalah kurangnya fasilitas untuk melaksanakan program tersebut seperti kendaraan yang akan digunakan untuk melakukan kunjungan ke bandara atau ke Lanud Sutan Sjahrir untuk menyambut pesawat TNI-AU yang akan mendarat. Dalam mengatasi hal ini sekolah hanya mengajak perwakilan dari siswa saja, biasanya anggota OSIS. Hambatan lain adalah waktu kunjungan atau latihan bersama dengan TNI-AU yang tidak pasti sehingga berjalannya program menjadi tersendat-sendat.

$\begin{array}{llr}\text { Peran TNI-AU } & \text { dalam } \\ \text { Melaksanakan } & \text { Program } & \text { Cinta } \\ \text { Dirgantara } & & \end{array}$
$\begin{array}{rrr}\text { Peran } & \text { TNI-AU } & \text { dalam } \\ \text { pelaksanaan } & \text { program } & \text { cinta }\end{array}$ dirgantara ini adalah sebagai pengajar yang mengajarkan siswa sikap-sikap nasionalisme yang dilakukan melalui pelatihan pramuka dan juga Paskibra. TNIAU juga menjadi model bagi siswa yang menggambarkan sosok nasionalis yang telah berjasa menjaga negara dari berbagai gangguan di angkasa. Selain itu TNI-AU juga memberikan sosialisasi kepada siswa dengan mengenalkan potensi-potensi wilayah udara nasional yang dimiliki oleh NKRI. Sejalan dengan pendapat (Sulthoni, 2016) yang mengemukakan bahwa keteladanan jauh lebih penting daripada memberikan pembelajaran secara verbal, karena keteladanan memberikan contoh 
melalui perbuatan dan tindakan nyata.

Peng-gembleng-an yang dilakukan oleh TNI-AU kepada seluruh siswa yang mengikuti kegiatan pramuka bertujuan untuk mempersatukan pikiran bahwa mereka semua sama dan harus bekerja sama untuk mencapai tujuan yang diinginkan. Dengan menyatukan sikap dan pikiran para siswa maka akan terbentuk kerja sama tim yang baik. Hal ini juga mendorong timbulnya sikap nasionalisme pada diri siswa. Soegito (Surono, 2017) mengungkapkan bahwa indikator dari sikap nasionalisme antara lain: rela berkorban, mengutamakan kesatuan dan persatuan, cinta tanah air, berjiwa pembaharuan dan pantang menyerah

Hal ini juga dilakukan untuk membentuk nasionalisme siswa dengan menyadarkan bahwa mereka memiliki banyak persamaan dalam kehidupan mereka antara satu dengan lainnya. Persamaan ini yang dijadikan sebagai alat untuk bersatu. Sikap nasionalisme dipengaruhi oleh beberapa faktor, seperti sejarah, ideologi, budaya etnik (etnisitas), agama, ekonomi, politik-birokrasi, hukum, militer (Muttaqin et al., 2016).

Dari kedelapan faktor tersebut 4 pertama disebut faktor kultural. Faktor ini berkaitan dengan emosi dan sentimen individu kepada individu yang lain. Faktor ini menjadi faktor yang rentan terjadi perpecahan karena perbedaan-perbedaan. Maka dari itu melalui TNI-AU dalam melakukan latihan bersama siswa maka terlebih dahulu menyatukan pikiran dan sikap bahwa mereka semua sama sehingga persatuan dan kerjasama antar siswa bisa terjalin.

Faktor 5 sampai 8 adalah faktor struktural yang berdasarkan dengan pertimbangan rasional. Aktualisasi dari faktor ini tergambar dari tindakan atau kebijakan negara dalam mengelola ekonomi, politik-birokrasi, hukum, dan militer. Adanya pengelolaan oleh pemerintah menunjukkan tidak adanya keberpihakan, keadilan, dan adanya ketidakpuasan dalam masyarakat, maka akan menimbulkan sikap primodialisme, dan bahkan separatisme. Pengenalan kedirgantaraan yang dilakukan oleh TNI-AU dilakukan untuk mengenalkan keunggulan strategis karena letaknya berada tepat di atas garis khatulistiwa. Pengenalan ini juga dilakukan untuk memberikan pemahaman bahwa kawasan kedirgantaraan Indonesia dapat diperuntukan untuk kepentingan kesejahteraan dan pertahanan nasional. 


\section{KESIMPULAN}

Cinta Dirgantara adalah
program unggulan di SMP
Angkasa, dalam program ini para
siswa melakukan beberapa
kegiatan seperti penyambutan
pesawat TNI-AU yang akan
mendarat, Pramuka, PBB. Semua
kegiatan tersebut adalah kegiatan
yang dilakukan bersama dengan
TNI-AU. Melalui kegiatan dalam
program ini ditanamkan nilai
nasionalisme pada diri siswa yang
tergambar melalui sikap-sikap
seperti, cinta tanah air,
mengutamakan persatuan dan
kesatuan, berjiwa pembaharuan
dan pantang menyerah. TNI-AU
berperan penting dalam
pelaksanaan program ini, sebagai
sosok yang menjadi teladan sikap
nasionalis dan mengajarkan siswa
sikap nasionalisme melalui
berbagai kegiatan yang dilakukan
bersama mereka.

\section{DAFTAR PUSTAKA}

Susilo, Adi, S. (n.d.). NasionalismeDemokrasi- Civil Society. 1, 1-15.

Aulia, L. Z., \& Trihantoyo, S. (2019). Strategi Kepala Sekolah Dalam Membangun Karakter Siswa Melalui Program Budaya Nasionalisme Di Mts Negeri 2 Surabaya. Insprasi Manajemen Pendidikan, VII(1).
Bakar, K. A. A., Noor, I. H., \& Widodo. (2018).

Penumbuhan Nilai Karakter

Nasionalis Pada Sekolah Dasar di Kabupaten Jayapura Papua. Cakrawala Pendidikan, 37(1), 42-56.

Basrowi \& Suwandi. (2008).

Memahami Penelitian

Kualitatif. Jakarta. Rineka

Cipta Budimansyah, D. (2010). Tantangan

Globalisasi Terhadap

Pembinaan Wawasan

Kebangsaan

dan Cinta Tanah Air di Sekolah. Jurnal Pendidikan

Penelitian, II, 7-13.

Fibrianto, A. S., \& Bakhri, S. (2018). Pelaksanaan Aktivitas Ekstrakurikuler Paskibra (Pasukan Pengibar Bendera) Dalam Pembentukkan Karakter, Moral Dan Sikap Nasionalisme Siswa Sma Negeri 3 Surakarta. Jurnal Moral Kemasyarakatan, 2(2), 75.

https:// doi.org/10.21067/j mk.v2i2.1970

Kusnaedi. (2016). Strategi Makro Pendidikan Karakter. Character Building Institute. Retrieved from http:/ / character-buildinginstitute.com/blog/post/3/ strategi-makro-pendidikankarakter 
Mulyasa, E. (2003). Manajemen Berbasis Sekolah, Cet. V, Bandung: PT Remaja Rosda Karya.

Muttaqin, T., Subiyono, A., Riyanto, D., \& Bachtiar, T. A. (2016). Membangun Nasionalisme Baru: Bingkai Ikatan Kebangsaan Indonesia Kontemporer (Issue March). Kementrian Negara Perencanaan Pembangunan Nasional (BAPPENAS).

Nihayah, S., \& Adi, A. S. (2014). Penanaman Nasionalisme Pada Siswa Madrasah Aliyah Negeri 1 Bojonegoro di Tengah Arus Globalisasi. Kajian Moral Dan Kewarganegaraan, 3(2), 829845.

Rawintina, N. I., \& Arsana, I. M. (2013). Penanaman Nilai Nasionalisme dan Patriotisme untuk Mewujudkan Pendidikan Karakter Pada Matapelajaran Pendidikan Kewarganegaraan

Siswa Kelas X SMA Negeri 4 Sidoarjo. Kajian Moral Dan Kewarganegaraan, 1(1), 3954.

Sulthoni, S. (2016). Penanaman Nilai-Nilai Budi Pekerti Di Sekolah Dasar. Sekolah Dasar: Kajian Teori Dan Praktik Pendidikan, 25(2), 100-108. https:/ / doi.org/10.17977/u m009v25i22016p100

Surono, K. A. (2017). Penanaman Karakter dan Rasa Nasionalisme pada KegiatanEktrakurikuler Pramuka di SMP N 4 Singorojo Kabupaten Kendal. 06(01). 